\title{
Gestational Sac vs Pseudosac
}

\author{
Ayesha Ajmi* \\ Bolton Foundation NHS Trust, UK
}

*Corresponding author: Ayesha Ajmi, Department of Obstetrics and Gynaecology, Bolton Foundation NHS Trust, Bolton, UK.

Received Date: January 15, 2021

Published Date: February 09, 2021

\section{Mini Review}

It is important to diagnose intrauterine pregnancy in the presence of empty gestational sac and not to confuse with pseudosac and avoid unnecessary investigations and follow up. Intrauterine gestational sac identification via ultrasonography has $97.6 \%$ specificity for the diagnosis of IUP, while the yolk sac visualization has $100 \%$ specificity [1].

Mean sac diameter (MSD) of $25 \mathrm{~mm}$ without an embryo is indicative of pregnancy failure, while MSD between 16 and $25 \mathrm{~mm}$ without an embryo is suggestive of possible pregnancy failure.

Since the incidence of ectopic pregnancies is approximately $2 \%$, a nonspecific intrauterine fluid collection with normal imaging of adnexa is more likely to represent an early intrauterine pregnancy.

Intradecidual sign - The intradecidual sign is the earliest US finding associated with an IUP. On TVUS, this sign typically can be seen at approximately 4.5 weeks of gestation, when the hCG is equal or greater than $1500 \mathrm{IU} / \mathrm{L}$, and/or when the mean sac diameter (i.e., the average measurement of the sac obtained in three planes) is $3 \mathrm{~mm}$ or greater.

The intradecidual sign is a small round fluid collection surrounded by an echogenic rim. It is eccentrically located within the endometrial cavity and should deviate the endometrial lining. This structure and its echogenic rim represent the chorionic cavity, implanting chorionic villi, and associated decidual tissue.

The double decidual sac sign (DDSS) is defined as two concentric echogenic rings of tissue surrounding an intraendometrial fluid collection that impress upon the endometrial stripe in an early IUP. Conversely, in an EP, the decidual reaction presents as only a single echogenic ring around the endometrial fluid collection [2].

A recent systematic review and meta-analysis reported that the DDSS predicted an IUP with a sensitivity of $81.8 \%$ and specificity of $97.3 \%$.

\section{Features of Pseudosac}

- $\quad$ Does not have an echogenic rim

- $\quad$ Tends to be located in the middle of the uterine cavity rather than embedded in the decidua

- $\quad$ Can change in shape during the scan

- May appear to be complex since it contains blood

When an obvious extrauterine pregnancy is not present, the ultrasonographic findings of an empty uterus, a pseudosac, an adnexal mass and/or free fluid have poor sensitivity for identifying a tubal pregnancy (Table 1).

Table 1:

\begin{tabular}{|c|c|}
\hline Gestational sac & Pseudosac \\
\hline Smooth, round or oval & irregular \\
\hline In central part of uterus & Other locations \\
\hline Beneath endometrium & Within endometrium \\
\hline $\begin{array}{c}\text { Double decidual sign (may not } \\
\text { always be present) }\end{array}$ & $\begin{array}{c}\text { Sharp edges with possible debris } \\
\text { in lumen }\end{array}$ \\
\hline
\end{tabular}

Intrauterine fluid collections that do not demonstrate the DDSS cannot be labelled as pseudosac associated with EPs. Such sonographic findings require follow-up until pregnancy location can be determined conclusively.

\section{Acknowledgement}

None.

\section{Conflict of Interest}

Author declare no conflict of interest.

\section{References}

1. Fylstra DL (2015) Avoiding misdiagnosing an early intrauterine pregnancy as an ectopic pregnancy. World J Obstet Gynecol 4(3): 58-63.

2. Richardson A, Hopkisson J, Campbell B, Raine-Fenning N (2017) Use of double decidual sac sign to confirm intrauterine pregnancy location prior to sonographic visualization of embryonic contents. Ultrasound Obstet Gynecol 49(5): 643-648. 